\title{
QUANDO A ESCOLA É UMA FLECHA \\ Educação Escolar Indígena e Territorialização na Amazônia
}

\author{
Gilberto César Lopes Rodrigues ${ }^{1}$
}

\section{RESUMO}

Apresentamos aqui um exame da escola diferenciada indígena nos processos de territorialização desses povos. Consideramos experiências escolares que envolvem a escola na ocupação, vigilância e posse do território e as analisamos a partir do conceito de Territorialização desenvolvido por Pacheco de Oliveira (1998) e Little (2002). Em seguida contrastamos os resultados da análise com o entendimento de Território expresso na normatização/legalização dessa modalidade escolar. Concluímos o trabalho argumentando que a inclusão de atividades escolares e sua efetivação ao longo do território, sobretudo em locais recuperados, fora do entorno do prédio escolar e da aldeia, é um modo encontrado por esses povos de voltar as atividades escolares para a manutenção territorial e identitária. Combinamos revisão bibliográrica e atividades de campo na coleta de dados recorrendo a questionários, entrevistas semi-estruturadas e diários de campo cuja análise envolveu recursos exploratórios, descritivos e interpretativos. A pesquisa se desenvolveu nos âmbitos dos Grupos de Pesquisa do CNPq "ISEAM - Indigenismo, Sociedade e Educação na Amazônia" e HISTEDBR-UFOPA e do Programa de Pósgraduação em Educação-PPGE-UFOPA.

Palavras-chave: Territorialização. Educação Escolar Indígena. Identidade Étnica.

\section{WHEN SCHOOL IS AN ARROW \\ Indigenous School Education and Territoriality in the Amazonia}

\begin{abstract}
We present here an examination of the differentiated indigenous school in the processes of territorialization of these peoples. We consider school experiences that involve the school in the occupation, surveillance and possession of the territory and analyze them from the concept of Territorialization developed by Pacheco de Oliveira (1998) and Little (2002). Then we contrast the results with the understanding of Territory expressed in the normatization / legalization of this school modality. We conclude the work by arguing that the inclusion of school activities and their fulfillment throughout the territory, especially in recovered places, outside the surroundings of the school building and the village, is a way found by these people to return school activities for territorial maintenance and identity. We combined

\footnotetext{
1 Doutor em Educação. Docente do Programa de Pós-Graduação em Educação da UFOPA; Líder do Grupo de Pesquisa do CNPq "Indigenismo, Sociedade e Educação na AmazôniaISEAM" e membro do HISTEDBR-UFOPA. E-mail: gilbertocesar@gmail.com
} 
bibliographic review, field activities for data collection using questionnaires, semistructured interviews, and fieldwork diaries whose analysis involved explorative, descriptive and interpretational resources. The research was developed within the scope of the CNPq Research Groups "ISEAM - Indigenism, Society and Education in the Amazon" and HISTEDBR-UFOPA and the Postgraduate Program in EducationPPGE-UFOPA.

Keywords: Territorialization. Educational School Education. Ethnic Identidad.

\section{CUANDO LA ESCUELA ES UNA FLECHA \\ Educación Escolar Indígena y Territorialización en la Amazonia}

\section{RESUMEN}

Presentamos aquí un examen de la escuela diferenciada indígena en los procesos de territorialización de esos pueblos. Consideramos experiencias escolares que involucran a la escuela en la ocupación, vigilancia y posesión del territorio y las analizamos a partir del concepto de Territorialización desarrollado por Pacheco de Oliveira (1998) y Little (2002). En seguida contrastamos los resultados con el entendimiento de Territorio expresado en la normatización / legalización de esa modalidad escolar. Concluimos el trabajo argumentando que la inclusión de actividades escolares y su efectividad a lo largo del territorio, sobre todo en locales recuperados, fuera del entorno del edificio escolar y de la aldea, es un modo encontrado por esos pueblos de volver las actividades escolares para el mantenimiento territorial y identidad. Combinamos revisión bibliográfica y actividades de campo para recolección de datos recurriendo a cuestionarios, entrevistas semiestructuradas y diarios de campo cuyo análisis involucró recursos exploratorios, descriptivos y interpretativos. La investigación se desarrolló en el ámbito de los Grupos de Investigación del CNPq "ISEAM - Indigenismo, Sociedad y Educación en la Amazonia" y HISTEDBR-UFOPA y del Programa de Postgrado en Educación-PPGE-UFOPA.

Palabras clave: Territorialización. Educación Escolar Indígena. Identidade Étnica.

\section{INTRODUÇÃO}

Após a promulgação da Constituição de 1988 a política de Estado assumidamente assimilacionista imposta aos indígenas desde a conquista foi substituída pela política de valorização da diferença e da diversidade cultural2.

2 Um bom exame dessa mudança de concepção pode ser encontrado em Souza Filho (1999). 
No campo da Educação Escolar Indígena consolidaram-se instrumentos jurídicos e normas oficiais de orientações à sua implantação que respeitassem, valorizassem e incentivassem os modos próprios de vida, de língua e de instituições das sociedades indígenas. Oficializou-se a criação da modalidade/categoria Educação Indígena no sistema nacional de educação fundamentada no fortalecimento da autonomia dos grupos étnicos permitindo a escola ser um agente dos interesses indígenas nos processos de fortalecimento identitário e consolidação territorial.

De sorte as regulamentações oficiais que normatizaram a escola indígena liberaram-na ao protagonismo indígenas Ihes assegurando controle sobre o processo de sua construção e consolidação permitindo-lhes estabelecer os conteúdos, os gestores, o calendário e os professores. Tais regulamentações seguiram a Constituição Federal (BRASIL, 1988) que estabeleceu "conteúdos mínimos para o ensino fundamental, de maneira a assegurar formação básica comum e respeito aos valores culturais e artísticos, nacionais e regionais" (BRASIL, 1988, art. 210), "ficando assegurada às comunidades indígenas a utilização de suas línguas maternas e processos próprios de aprendizagem" (BRASIL, 1988, art. 210, § 20).

Tais conquistas foram consideradas importantes e celebradas pelos indígenas e por grande parte dos indigenistas. Abriu-se caminho para orientar positivamente o processo de implementação de escolas indígenas em torno dos interesses dos próprios indígenas. Além de poder mobilizar as atividades da escola para a recuperação cultural, a legislação seguinte reafirmou "a centralidade do território para o bem viver dos povos indígenas e seus processos formativos" (BRASIL, 2003, p. 286) induzindo, coerentemente, a implantação dessa modalidade de educação nas "escolas em terras habitadas por comunidades indígenas" (Idem).

Porém, a experiência mostra que há uma grande distância entre o plano teórico das garantias legais e o da sua implementação. Dificuldades cuja superação de certa forma impelem indígenas a se organizarem para conquistar a efetivação de seus direitos. 
No caso do funcionamento da educação indígena, no nível infantil e fundamental, a prefeitura de Santarém-PA vem alegando dificuldades ${ }^{3}$ e, no nível médio, o estado do Pará vem impondo a criação de um sistema de aulas a distância via satélite, de modo que, a luta pela implantação da educação diferenciada tem encontrado obstáculos.

As mobilizações das lideranças indígenas e suas associações formais para superar as dificuldades e impor os elementos indígenas no interior das atividades escolares tem persistido e conduzido a ganhos na região. No município de Santarém, são quarenta e quatro escolas indígenas cadastradas na Secretaria Municipal de Educação ${ }^{4}$ (SEMED), três no município de Belterra 5 e três no município de Aveiro6, representando treze diferentes designações étnicas ${ }^{7}$ espalhados por sessenta e quatro povoamentos que reivindicam identificação e demarcação territorial indígena.

A conquista das escolas e a reelaboração a ela emprestada tem se tornado importante elemento aglutinador das sociedades indígenas brasileiras (sobretudo as de alto contato interétnicos) ganhando dimensões que tem superado a valorização, resgate e transmissão cultural. Além dessa dimensão cultural a apropriação da Escola em sua tradução diferenciada tem se tornado instrumento de formação política, coesão social e defesa do território, contribuindo para a permanência dessas sociedades, sobretudo em contextos marcadamente de resgate e reafirmação étnica envolto em caos fundiário tendo no Estado agente de desagregação, desde aprovando

\footnotetext{
3 Tramita processo entre a prefeitura de Santarém e o governo do Pará solicitando a devolução ao estado das escolas indígenas sob sua jurisdição. Em audiência pública ocorrida em setembro de 2017 foi criado um GT com representantes das três esferas de governo e indígenas para discutir a questão. O processo encontra-se inconcluso.

${ }_{4}^{4}$ Fonte: Coordenadoria de Educação Indígena da Secretaria Municipal de Educação da Prefeitura de Santarém - CEI-SEMED-STM, (2018).

5 Fonte: COMEB, Conselho Municipal de Educação de Belterra (2018).

6 Fonte: SEMED de Aveiro, 2018.

7 Arapium, Borari, Tapajó, Munduruku, Tapuia, Jaraki, Tupinanbá, Kumaruara, Kara Preta, Tupaiú, Apiaká, Arara Vermelha e Maitapú. Fonte: Conselho Indígena Tapajós Arapiuns CITA, 2018.
} 
planos de manejos madeireiros no interior da Terra Indígena (T.I.)8, até permutando9 aquelas terras sem consulta prévia, e, de outro, a grilagem de terras, extração ilegal de madeira e ameaças de morte.

Em contextos assim de explicita ação das forças de "ponta de lança" de expansão do capital é importante um exame do papel da escola e de seus objetivos educacionais procurando desvelar se a escola deveria ficar neutra, ou se deveria incluir no currículo e, portanto, ensinar, defesa do território.

Responder a essa questão conformou-se na força motriz dessa pesquisa. Essa preocupação emergiu no bojo de nossa pesquisa anterior sobre o papel da escola na reafirmação étnico-cultural dos Borari e Arapium (RODRIGUES, 2015, 2016). Aqui focamos os elementos de territorialidade nas atividades escolares que acompanhamos e desvelou-se que envolviam subidas longas ao interior da floresta articuladas com vigilância e defesa do território.

Após uma incursão pelo conceito de territorialidade em Pacheco de Oliveira (1998) e Little (2002) apresentada na seção 1, e na legislação e normatização da educação escolar indígena relatada na seção 2, há uma breve etnografia dos Borari e Arapium do Maró para situarmos uma experiência executada pelos professores indígenas de lá que vem se configurando como importante meio de utilização da escola diferenciada como instrumento de defesa territorial, somando-se aos aspectos de fortalecimento identitário indígena. Concluímos o trabalho apontando a importância que tal prática tem representado para a manutenção física e identitária desses povos.

\footnotetext{
8 Em 2015 o Conselho Intercomunitário Indígena Arapium-Borari (COIIAB) foi notificado pelos vigilantes ambientais da T.I. Maró da existência de seis planos de manejos aprovados pela Secretaria de Meio Ambiente e Sustentabilidade do Estado do Pará com extensões parciais e totais de superposição ao território da T.l. Maró.

9 O aprofundamento dos problemas fundiários da região teve ápice quando o Governo do Estado do Pará através do ITERPA permutou com donos de planos de manejos madeireiros nas terras do projeto Trairão, que foram destinadas aos Kayapó, por terras na Gleba Nova Olinda I, na qual localiza-se a T.I. Maró. Conferir em: http://anoreg.org.br/index.php?option=com_content\&view=article\&id=7713:imported_7683 \& catid $=54 \& \mid t e m i d=184$.
} 
A pesquisa envolveu trabalho de campo com acompanhamento in loco das atividades por quatro anos consecutivos desde 2014 totalizando mais de 600 horas de acompanhamento com coleta de dados via caderno de campo, entrevistas estruturadas e semi-estruturadas e se desenvolveu no âmbito do Grupo de Pesquisa do CNPq "Indigenismo, Sociedade e Educação na Amazônia-ISEAM" e do Grupo de Estudos e Pesquisa em História, Sociedade e Educação no Brasil - HISTEDBR da Universidade Federal do Oeste do Pará (UFOPA).

Entendemos que este trabalho se situa no campo da Sociologia da Educação ao olhar o objeto da perspectiva da Educação, da Antropologia e do Direito. Metodologicamente realizamos uma revisão bibliográfica em Pacheco de Oliveira, Litte e na Normatização escolar brasileira para compreender o conceito de Territorialidade, e realizamos observaçãoparticipativa ${ }^{10}$ das atividades-escolares-foco ${ }^{11}$. Do ponto de vista temporal, analisamos nosso objeto no contexto da implantação da chamada "Nova República" até os dias atuais. Neste estudo, os trabalhos de campo antecederam a revisão teórica ${ }^{12}$.

\section{TERRITORIALIZAÇÃO, IDENTIDADE E SEUS PROCESSOS NO BAIXO TAPAJÓS}

Territorialização ${ }^{13}$ pode ser concebida enquanto $O$ processo de domínio e significação de um território através de relações sociais e materiais da população que nele habita. E, território, o espaço geográfico composto de um ambiente biofísico. A terra, água, vegetação e fauna de uma região compõem a base das relações de alimentação física e cultural de seus habitantes e, territorialização, o processo de domínio e significação sobre

\footnotetext{
10 Em forma de 5 vivencias que duraram em média 8 dias.

11 Escolhemos as atividades escolares da semana do 7 de setembro, chamada "Semana da Pátria", como atividades-chave para o entendimento do objeto. Elas são nossas atividadesescolares-foco e são elas que estão referidas nesse trabalho.

12 A conexão entre Territorialização e Educação só me ocorreu após os estudos que realizei sobre Escola e Reafirmação Ética (RODRIGUES, 2016).

${ }_{13}$ De modo geral optamos pelo emprego do termo Territorialização em relação a Territorialidade por carregar uma dimensão processual mais impositiva do que este, por trazer o dinamismo de modo mais forte e indicar um processo aberto que está ocorrendo o tempo todo.
} 
eles. Little (2002, p. 3) nos ajuda nessa compreensão ao afirmar que "defino a territorialidade como o esforço coletivo de um grupo social para ocupar, usar, controlar e se identificar com uma parcela específica de seu ambiente biofísico, convertendo-a assim em seu 'território'".

Porquanto ambiente biofísico, o território envolve a terra, a água, a floresta, as pessoas, a fauna que sustentam concretamente as relações e interrrelações das quais emergem as representações que conformam a identidade. Envolve processos de construção identitária pessoal e coletiva a partir de relações estabelecidas entre indivíduos e deles para com todos os elementos que compõe seu território cujas relações complexas informam e geram significados que sustentam uma idiossincrasia individual e coletiva. Territorialização envolve, portanto, elementos materiais e imateriais.

Nos processos de territorialização emergem elementos imateriais como a representação dos encantados que moram nas cabeceiras dos igarapés ou a força do pajé, mas organicamente imbricados no contexto material, a própria terra, floresta e fauna que conformam o ambiente significativo, âncora das representações e gerador do aspecto identitário. Nestes termos, afirmar pertencer a uma etnia é afirmar compartilhar significados coletivos gerados por relações sociais de um grupo (ou indivíduo) com o contexto imaterial e material que participa mediado pelo território. É, portanto, uma afirmação que envolve territorialidade.

Construindo o conceito de Territorialização João Pacheco de Oliveira (1998, p. 55) em seu clássico "Etnologia dos Índios Misturados?", aponta que:

[...] a noção de territorialização é definida como um processo de reorganização social que implica: 1) a criação de uma nova unidade sociocultural mediante $\mathrm{O}$ estabelecimento de uma identidade étnica diferenciadora; 2) a constituição de mecanismos políticos especializados; 3) a redefinição do controle social sobre os recursos ambientais; 4) a reelaboração da cultura e da relação com o passado (Grifos nossos).

Apesar de não explicitar a necessidade de uma base territorial para a 'noção de territorialização' o autor reconhece que ela envolve 'controle social sobre recursos ambientais'. Ora, onde estão os recursos ambientais? 
Em alguma base territorial. Voltaremos a esse tema mais adiante. Por ora é importante reter do fragmento acima que territorialização é um processo e requer aceitar que ocorre em espaços e tempos determinados, e que deve ser considerado as experiências históricas dos sujeitos ancoradas em um ambiente biofísico, a própria condição histórica a que está submetido e todos esses elementos retroagindo sobre os sujeitos. Assim, as experiências ganham significado na medida em que são abrigadas no padrão identitário dominante do grupo étnico ao qual pertencem, alimentando e dando vida aos significados e agregando ao sentimento de pertencimento e, depois, em relação de contraste com outras identidades sociais, como a dominante, por exemplo.

Com efeito, os grupos indígenas (e todos os demais) constroem sua identidade não apenas a partir da relação histórica entre si e com seu território, mas com outras etnias. É neste contexto que Pacheco de Oliveira, recorrendo a Fredrick Barth ${ }^{14}$ para compreender a emergência ética no nordeste brasileiro, considera "um grupo étnico como um tipo organizacional, onde uma sociedade se utilizava de diferenças culturais para fabricar e refabricar sua individualidade diante de outras com que estava em um processo de interação social" (PACHECO DE OLIVEIRA, 1998, p. 55).

Em sociedades de alto grau de relações interétnicas "é importante refletir mais detidamente sobre o contexto intersocietário no qual se constituem os grupos étnicos" (Idem). Logo, não é o que perderam que conta, mas o que construíram e reelaboraram ao longo de suas históricas relações intersocietárias e que os mantém vivos e etnicamente referenciados.

Aliás, no campo da batalha jurídica pelo reconhecimento e demarcação de territórios indígenas, deve-se contrastar esse processo dinâmico de reconstruções identitárias à chamada 'etnologia das perdas'

\footnotetext{
14 Antropólogo Social norveguês (1928-2016) que consolidou uma abordagem para o estudo da etnia focada no desenvolvimento das negociações sobre as fronteiras geográficas entre grupos de pessoas. Ou seja, pretendeu reelaborar as noções antropológicas de culturas como entidades limitadas e fechadas. Ao contrário, ela estaria em constante movimento e aberta, sobretudo, nas relações de interface entre grupos.
} 
fartamente utilizada pelas estruturas do Estado para combater os processos de demarcação de território. Contrastá-las

[...] põe em equívoco a pretensão de reportar-se a uma condição de isolamento localizada no passado para vir a explicar os elementos definidores de um grupo étnico, cujos limites seriam construídos pelos próprios membros daquela sociedade" (PACHECO DE OLIVEIRA, 1998, p. 55).

Argumentos dessa natureza tem operado nos tribunais para paralisar processos de demarcação territorial alegando falta de "indianidade" aos solicitantes ${ }^{15}$. É a etnologia das perdas presentes no campo jurídico e amplamente aceita pelo senso comum que mede arbitrariamente os indígenas de hoje em relação ao índio à época da chegada dos europeus. Ou seja, do ponto de vista da etnologia das perdas seria mais índio aquele que mais conservou características do período da conquista europeia, apesar de incorrer em anacronismo.

Diante deste quadro, a importância do território ganha duplo aspecto. De participar ativamente do processo identitário e de manter a vida física dos indígenas. Em um contexto de homogeneização cultural, constante avanço do agronegócio e de exploração predatória dos recursos naturais ${ }^{16}$, possuir um território permite as populações indígenas mais adequadamente (re)construir sua dimensão simbólica e espiritual e produzir e coletar para manter a vida. Consequentemente, a relação entre o indivíduo e o grupo étnico seria mediada pelo território e a "sua representação poderia remeter não só a uma recuperação mais primária da memória, mas também às imagens mais expressivas da autoctonia" (PACHECO DE OLIVEIRA, 1998 p. $65)$.

A mediação do território implica novamente considerar duas faces da territorialização. Uma que envolve os elementos imateriais geradores de

15 É ilustrativo dessa situação a sentença proferida em 2015 pela Justiça Federal de Primeiro Grau do Pará, segunda vara da subseção de Santarém (disponível em: Disponível em: http://www.prpa.mpf.mp.br/news/2015/arquivos/Sentenca_Tl_Maro.pdf.) na qual é contestada a condição de indígena dos povos da Terra Indígena Maró. Na argumentação da sentença é explicito a analise via antropologia das perdas.

16 Uma boa síntese desse avanço pode ser obtida em Almeida, et al (2010) e Saver e Pereira (2006).

Revista Exitus, Santarém/PA, Vol. 8, №3, p. 396 - 422, SET/DEZ 2018. 
identidade e de sentido de pertencimento a um grupo. Outra que envolve propriamente a terra, uma base territorial. Em um contexto de ameaça à posse dos territórios, defender que os processos de territorialização envolvem o domínio e posse de uma base territorial fixa é imprescindível como condição sine qua non para a preservação física e cultural dos povos indígenas.

Em fortalecimento aos processos de territorialização articulado com a manutenção identitário, inúmeros grupos indígenas no Brasil, sobretudo de alto contato interétnicos, têm optado pela introdução de educação escolar em seus territórios. Considerando que no longínquo ano de 1975 o antropólogo Silvio Coelho dos Santos ao elaborar um relatório sobre a realidade dos Postos Indígenas de toda região sul do Brasil constatava que "a função da educação escolar vem sendo usada junto às comunidades indígenas para manter os quadros de dominação exercidos pela sociedade nacional" (SANTOS, 1975, p. 12) e que "a educação foi sempre um instrumento estratégico para se atingir os objetivos da sociedade nacional de submeter ou diluir os indígenas na sociedade nacional" (Idem, p. 53) é legítimo questionar: qual o papel da educação escolar nas sociedades indígenas atualmente? Qual seu papel nos processos de territorialização e fortalecimento identitário indígena?

Para compreendermos o papel da Escola nos processos de manutenção territorial é elucidativa o entendimento segundo o qual $\circ$ processo de territorialização é,

[...] justamente, o movimento pelo qual um objeto políticoadministrativo vem a se transformar em uma coletividade organizada, formulando uma identidade própria, instituindo mecanismos de tomada de decisão e de representação, e reestruturando as suas formas culturais (inclusive as que o relacionam com o meio ambiente e com o universo religioso) (PACHECO DE OLIVEIRA, 1998, p. 56).

Apesar de no fragmento a noção de "objeto político-administrativo" se referir às estruturas estatais de grande porte que conformam e orientam um país ou nação, entendemos que ela fornece luz para um exame da 
Escola enquanto legítima estrutura político-administrativa representativa, deliberativa e promotora da territorialização.

A experiência escolar que está sob exame se mostra importante instrumento de territorialização na medida em que se fez instância organizadora da coletividade, contribuindo para a consolidação identitária, tanto própria como dos indígenas, através da incorporação dos saberes e práticas indígenas em suas atividades e da abertura de novos canais de tomadas de decisões que vem impactando suas formas de relacionamento com o meio ambiente e com a dimensão simbólica.

Ademais, essa reelaboração da atividade escolar é importante na região amazônica do baixo Tapajós ${ }^{17}$ na medida em que desde 1998 vários grupos étnicos, dos quais muitos eram tidos como extintos, tem requerido junto aos órgãos oficiais o reconhecimento indentitário indígena e, consequentemente, sua territorialização ${ }^{18}$. Atualmente sessenta e quatro grupos comunitários requerem reconhecimento indígena na região do baixo Tapajós demandando à FUNAI o processo de identificação e demarcação territorial19. Somente no município de Santarém, há quarenta e quatro escolas registradas como indígenas 20 .

Porém, nossa questão permanece: em que medida essas escolas participam dos processos de territorialização e estão mobilizadas para a manutenção territorial? Para enfrentar esta questão em um caso concreto mais a frente examinaremos a educação escolar da terra indígena Maró.

Antes, porém, é importante averiguar no campo da lei e normas que dizem respeito a educação escolar indígena o modo pelo qual aparece o conceito de território e seus correlatos para o entendimento de seu significado no campo jurídico.

\footnotetext{
17 Baixo Tapajós compreende a região de sua desembocadura no rio Amazonas e envolve os municípios de Santarém, Belterra e Aveiro.

18 Ver: Ioris (2009) e Rodrigues (2016).

19 Fonte: Conselho Indígena Tapajós-Arapium (CITA), 2017.

20 Fonte: Coordenação de Educação Indígena - SEMED de Santarém-PA.
} 


\section{TERRITÓRIO E LEGISLAÇÃO: sentido e significado}

É consenso dentre os indigenistas que a Constituição brasileira de 1988 inovou em matéria de reconhecimento dos direitos indígenas. Essa foi a primeira constituição que dedicou um capítulo inteiro21 a eles, no qual o artigo 231 sintetiza essa conquista:

Art. 231. São reconhecidos aos índios sua organização social, costumes, línguas, crenças e tradições, e os direitos originários sobre as terras que tradicionalmente ocupam, competindo à União demarcá-las, proteger e fazer respeitar todos os seus bens.

Ao reconhecer aos índios sua organização, costumes, línguas, crenças e tradições reconhece-se o direito deles em participar nas atividades que os envolvem. Tal é o caso das atividades escolares. Ou seja, se a escola é um locus privilegiado de promoção, questionamentos e inovação dos costumes, crenças, tradições, língua e organização de uma comunidade, então, aos indígenas, não pode ser diferente. A escola deve participar ativamente na promoção da organização social, simbólica e geográfica, e, portanto, envolver o território em suas atividades.

O termo território e seus correlatos territorialidade e territorialização ocorre diversas vezes nas leis vigentes. Na Constituição federal de 1988, por exemplo, seu primeiro registro ocorre no artigo que universaliza a igualdade jurídica e marca o significado do conceito:

Art. 50 Todos são iguais perante a lei, sem distinção de qualquer natureza, garantindo-se aos brasileiros e aos estrangeiros residentes no País a inviolabilidade do direito à vida, à liberdade, à igualdade, à segurança e à propriedade, nos termos seguintes:

[....]

$X V$ - É livre a locomoção no território nacional em tempo de paz, podendo qualquer pessoa, nos termos da lei, nele entrar, permanecer ou dele sair com seus bens (BRASIL, 1988) (Grifos nossos).

Ao permitir a locomoção em todo território nacional em tempo de paz, está se tomando o termo pelo seu significado geográfico de indicar a porção de terra, ou a área geográfica que conforma o país e sobre a qual é

21 Sob o título: "Dos Índios" o capítulo VIII da Constituição federal de 1988 apresenta dois artigos (231 e 232) e sete parágrafos inteiramente dedicados aos direitos dos povos originários do país. 
permitida e jurisdicionada à locomoção. Ou seja, território é compreendido como sinônimo de espaço geográfico concreto enquanto espaço geográfico possível de ser utilizado para locomoção.

Essa sinonímia de significado entre território e espaço geográfico de um país ou parte dele é constante na Constituição de 1988, sendo, também, exemplar o artigo abaixo:

Art. 225. Todos têm direito ao meio ambiente ecologicamente equilibrado, bem de uso comum do povo e essencial à sadia qualidade de vida, impondo-se ao Poder Público e à coletividade o dever de defendê-lo e preservá-lo para as presentes e futuras gerações.

[...]

III - definir, em todas as unidades da Federação, espaços territoriais e seus componentes a serem especialmente protegidos, sendo a alteração e a supressão permitidas somente através de lei, vedada qualquer utilização que comprometa a integridade dos atributos que justifiquem sua proteção (BRASIL, 1988).

Definir espaços territoriais para serem especialmente protegidos ecologicamente para garantir ambiente equilibrado significa definir áreas físicas de florestas, terras e águas, enfim, delimitar geograficamente ecossistemas para facilitar sua proteção. Ou seja, mais uma vez o termo território, através do correlato 'espaços territoriais', significa algum espaço físico geográfico concretamente existente em uma região do planeta.

Nas regulamentações infraconstitucionais que normatizam e orientam a educação indígena o termo território e seus correlatos também aparecem. Na Lei de Diretrizes e Base da Educação Nacional (LDB), Lei no 9394 de 1996, o termo ocorre duas vezes. Uma para designar os territórios da união enquanto unidades federativas distintos dos estados e, a outra, conforme abaixo:

Art. 87. É instituída a Década da Educação, a iniciar-se um ano a partir da publicação desta Lei.

[...]

$\S 3$ - O Distrito Federal, cada Estado e Município, e, supletivamente, a União, devem:

$[\ldots]$

IV - Integrar todos os estabelecimentos de ensino fundamental do seu território ao sistema nacional de avaliação do rendimento escolar (BRASIL, 2017) (Grifos nossos). 
Consoante o significado do termo utilizado na Constituição Federal, no fragmento da Lei n 9394/1996 acima, o termo território também indica área geográfica na medida em que compete aos estados, municípios e a união integrar os estabelecimentos de ensino presentes em sua jurisdição geográfica, em seu território ao sistema nacional de avaliação. Mais uma vez território é sinônimo de espaço geográfico enquanto área de abrangência jurisdicional de um estado ou município.

Posteriormente, a lei $n^{\circ} 13.005$ de 25 de junho de 2014 que institui o Plano Nacional de Educação (BRASIL, 2014) para o período de 2014-2024 inclui o termo território e seus correlatos. Nessa lei há o registro de cinco ocorrências, todas consonantes ao entendimento constitucional segundo o qual território é sinônimo de área geográfica de abrangência/cobertura/atuação jurisdicional.

Porém, as ocorrências mais interessantes para o propósito de nossa pesquisa estão nas diretrizes para o funcionamento das escolas indígenas (BRASIL, 1999) e nas diretrizes curriculares nacionais para a educação indígenas (BRASIL, 2012). Nelas os parâmetros para utilizar atividades escolares em processos de territorialização estão mais explicitos.

Em 1999 o Conselho Nacional de Educação (CNE) por meio da Câmara de Educação Básica (CEB) torna público a primeira normatização para a educação indígena no contexto da Nova República. Através da Resolução 03 de 10 de dezembro de 1999 são estabelecidas as Diretrizes Nacionais para o funcionamento das escolas indígenas 22 (Diretrizes). A resolução, apesar de não conter elementos explícitos que articulem o uso da escola nos processos de territorialização, trouxe elementos importantes para estes processos na medida em que the reconheceu o funcionamento com normas próprias visando a manutenção da diversidade étnica.

De sorte, as Diretrizes contribuíram para

Art. $1^{\circ}$ Estabelecer, no âmbito da educação básica, a estrutura e o funcionamento das Escolas Indígenas, reconhecendo-lhes a

22 Disponível em: http://portal.mec.gov.br/cne/arquivos/pdf/CEB0399.pdf. 
condição de escolas com normas e ordenamento jurídico próprios, e fixando as diretrizes curriculares do ensino intercultural e bilíngüe, visando à valorização plena das culturas dos povos indígenas e à afirmação e manutenção de sua diversidade étnica (BRASIL, 1999).

As diretrizes para o funcionamento das escolas indígenas (BRASIL, 1999) além de favorecer a preservação e recuperação linguística e culturais, avançaram também no reconhecimento da centralidade do território para seu bom funcionamento, na medida em que:

Art. $2^{\circ}$ Constituirão elementos básicos para a organização, a estrutura e o funcionamento da escola indígena:

I - Sua localização em terras habitadas por comunidades indígenas, ainda que se estendam por territórios de diversos Estados ou Municípios contíguos (BRASIL, 1999).

Ainda que de forma pouco explícita, depreende-se que a habitação real em uma localização geográfica, o território, constitui elemento básico para a organização, a estrutura e o funcionamento das escolas indígenas.

Em 2002 outra normatização importante foi publicada pelo Ministério da Educação, através do Conselho Nacional de Educação. Em, 22 de junho deste ano a Resolução CNE/CEB-05/2012 definiu as Diretrizes Curriculares Nacionais para a Educação Escolar Indígena na Educação Básica (BRASIL, 2002), "pautadas pelos princípios da igualdade social, da diferença, da especificidade, do bilinguismo e da interculturalidade, fundamentos da Educação Escolar Indígena" (Idem).

As Diretrizes Curriculares Nacionais (DCN) estabeleceram os objetivos da educação básica indígena determinando necessidade de zelar pela preservação cultural e territorial dos povos indígenas.

Art. $2^{\circ}$ As Diretrizes Curriculares Nacionais para a Educação Escolar Indígena na Educação Básica têm por objetivos:

$[\ldots]$

VII - Zelar para que o direito à educação escolar diferenciada seja garantido às comunidades indígenas com qualidade social e pertinência pedagógica, cultural, linguística, ambiental e territorial, respeitando as lógicas, saberes e perspectivas dos próprios povos indígenas (BRASIL, 2002). 
Zelar pela preservação cultural e territorial através das atividades escolares foi um importante ganho que as DCN proporcionaram. Avançando nesse ganho essas diretrizes realimentaram a normatização precedente (re)afirmando que:

Art. $4^{\circ}$ Constituem elementos básicos para a organização, a estrutura e o funcionamento da escola indígena:

I - A centralidade do território para o bem viver dos povos indígenas e para seus processos formativos e, portanto, a localização das escolas em terras habitadas por comunidades indígenas (BRASIL, 2012).

Reconhecer a centralidade do território para o bem viver dos povos indígenas através de uma legislação voltada para normatizar a escola indígena é permitir a elas se impor a tarefa de preservação territorial. Mais adiante nessa DCN, Resolução CNE/CEB-05/2012, seu artigo sétimo explicitou a possiblidade de articulação entre as atividades escolares e defesa territorial.

Art. $7^{\circ}$ A organização das escolas indígenas e das atividades consideradas letivas podem assumir variadas formas, como séries anuais, períodos semestrais, ciclos, alternância regular de períodos de estudos com tempos e espaços específicos, grupos não-seriados, com base na idade, na competência e em outros critérios, ou por forma diversa de organização, sempre que o interesse do processo de aprendizagem assim o recomendar.

[...]

$\S 3^{\circ}$ A Educação Escolar Indígena deve contribuir para o projeto societário e para o bem viver de cada comunidade indígena, contemplando ações voltadas à manutenção e preservação de seus territórios e dos recursos neles existentes (BRASIL 2012).

A organização das atividades das escolas indígenas, além de poder contar com calendário diferenciado e ciclos alternativos demandada pelos interesses culturais, ecológicos e sociais dos indígenas deve contribuir para ações voltadas à manutenção territorial e preservação dos recursos neles existentes.

Portanto, no campo das leis e normatização da educação indígena o conceito de território e seus correlatos significam a extensão espacial geográfica que habitam incluindo todo ambiente biofísico que conformam sua identidade indígena. 
De modo prático, poderíamos dizer que território corresponde a área geográfica das diversas reservas, áreas ou terras indígenas requisitadas, incluindo seus recursos naturais, nas quais os indígenas habitam e sem as quais a etnia desapareceria enquanto identidade e modo de vida diferenciados.

\section{ESCOLA E TERRITORIALIZAÇÃO NA TERRA INDÍGENA MARÓ: descrevendo e interpretando um caso concreto}

A Terra Indígena Maró (TI Maró) está localizada na Amazônia brasileira, no estado do Pará, no interior do município de Santarém ${ }^{23}$, estado do Pará. É composta por três aldeias situadas à margem esquerda do rio Maró habitadas por duzentas e sessenta pessoas. Este rio é afluente do rio Arapiuns e desaguam no rio Amazonas, através do rio Tapajós. A superfície da T.l. Maró é de 42.373 hectares e o perímetro de $131 \mathrm{~km}^{24}$. O acesso, a partir de Santarém, se dá por meio fluvial, sendo que, em barco 'de linha25', a viagem demora em torno de $12 \mathrm{~h}$ até a primeira aldeia e $14 \mathrm{~h}$ até a última.

Os Borari e os Arapium são as etnias dos indígenas moradores históricos da T.I. Maró. Os Arapium habitam as aldeias de São José III e Cachoeira do Maró e os Borari a aldeia de Novo Lugar. Os Borari e os Arapium são falantes do português. Apesar da razoável quantidade de registro da existência do aldeamento dos Borari e dos Arapium e, consequentemente, dos próprios Borari e dos Arapium, estes, junto com as demais sessenta e quatro comunidades $^{26}$ que reivindicam atualmente seu pertencimento étnico no baixo Tapajós, eram dados como extintos pelos documentos oficiais. Nossa

${ }^{23}$ O município de Santarém está localizado na mesorregião do Baixo amazônas, no Oeste do estado do Pará, as margens de dois grandes rios, o Tapajós e o Amazonas.

${ }_{24}$ Dados retirados do resumo do relatório circunstanciado de identificação e delimitação da Terra Indígena Maró, disponível em:

http://pesquisa.in.gov.br/imprensa/jsp/visualiza/index.jsp?jornal=1 \&pagina=36\&data=10/10/2 011.

25 Barcos de linha são aqueles autorizados pela marinha brasileira a transportar passageiros em horários e preços teoricamente pré-fixados entre o Estado e os empresários da navegação. No caso da TI Maró, dois barcos 'de linha' atendem seus moradores. Eles descem do Maró para Santarém aos sábados e um retorna nas quartas-feiras enquanto o outro retorna nas quintas-feiras.

26 Fonte: Conselho Indígena Tapajós Arapiuns - CITA. 
hipótese e que ocorrera um ativo processo de invisibilização ${ }^{27}$ posto em curso para assegurar a existência física decorrente do extermínio levado a cabo durante o brutal processo de colonização conduzido na região.

O processo de saída da invisibilidade e, portanto, de reafirmação étnica ${ }^{28}$, foi detonado por vários fatores: o contexto jurídico favorável decorrente da Constituição de 1988, necessidade de defesa do território devido aumento dos conflitos fundiários e por recursos naturais, ao conhecimento que os indígenas obtiveram dos avanços legais resultantes da promulgação da constituição de 1988, todos impulsionados pelo conhecimento de outros movimentos etnogênicos regionais e nacionais (RODRIGUES, 2016).

Decorrente deste contexto, no início dos anos 2000 moradores de três comunidades à margem do rio Maró (Novo Lugar, Cachoeira do Maró e São José III) iniciaram movimento de afirmação étnica indígena ${ }^{29}$ protocolando junto aos órgãos oficiais essa demanda. Como resultado, a Fundação Nacional do Índio (FUNAI) inicia os procedimentos oficiais para o reconhecimento, delimitação e homologação da terra indígena. Em um processo lento somente em 2008 a FUNAl instaura o Grupo Técnico de Trabalho de Identificação e Demarcação cujo relatório só fora publicado no Diário Oficial da União em julho de $2011^{30}$. Nele é atestado a existência e ocupação tradicional por indígenas Borari e Arapium no território que viria a ser demarcado como Terra Indígena Maró, sugerindo ao Estado sua demarcação.

Paralelamente ao trabalho de delimitação e demarcação da FUNAI, em 2006 os indígenas solicitam junto à Secretaria Municipal de Educação de Santarém (SEMED) a transformação de suas escolas (cada uma das três

\footnotetext{
27 Maiores detalhes em loris (2009) e Rodrigues (2016).

${ }^{28}$ Bartolomè (2006) apresenta uma boa síntese desse processo na América Latina.

29 O movimento de reafirmação étnica dos Borari e Arapium do Maró se inserem em um movimento de etnogênese mais abrangente que envolveu a região do baixo rio Tapajós desde 1990. Para mais informações ver loris (2009).

30 Para conferir o resumo do laudo antropológico publicado no Diário Oficial da União acesse:

http://pesquisa.in.gov.br/imprensa/jsp/visualiza/index.jsp?.jornal=1 \&pagina=36\&data=10/10/2 011
} 
comunidades possui uma escola) em Escolas Indígenas. Para tanto, as escolas das três aldeias foram reunidas de modo a compor uma organização do tipo polo-anexas, ficando como polo a escola da aldeia da Cachoeira do Maró31. Sua centralidade geográfica determinou esta decisão.

No ano seguinte conquistaram a inclusão de dois componentes curriculares nas atividades da escola que mais conforma a educação diferenciada: Notório Saber e Língua Indígena Nheengatu. A inclusão destes componentes no currículo escolar foi uma exigência das lideranças indígenas que solicitaram junto a Secretaria Municipal de Educação (SEMED) de Santarém-PA a inclusão de conteúdos que contemplassem de alguma forma a educação diferenciada. A partir de 2010 ocorreu a introdução destas aulas e intermitentemente a SEMED, a UFOPA e algumas ONGs da região oferecem cursos e formações em língua indígena.

A disciplina de Nheengatu ocupa duas horas de aulas semanais para todas as turmas do fundamental existentes nas escolas das aldeias. É usado uma espécie de apostila montada pelo professor que procura conectar as palavras as atividades corriqueiras da aldeia. Inicia-se pelos pronomes pessoais, depois é acrescentado adjetivos e sucessivamente as frases vão se complexificando e alongando e mais apropriadamente designando $\mathrm{O}$ contexto vivido.

O Notório Saber, em tese, teria assegurada o protagonismo dos "mais velhos" e ficaria responsável pelo ensinamento dos saberes históricos ainda preservados e que conformam a etnia e dão sentido à sua diferenciação cultural em relação à sociedade hegemônica. Para tanto, não seria exigida formação acadêmica universitária para compor o quadro docente dessa disciplina, fato que se confirmou em algumas escolas e foi reelaborado em outras.

Porém, em novembro de 2014 todo esse processo de construção da escola diferenciada, de reafirmação étnica e de demarcação do território

${ }^{31}$ Maiores detalhes da organização escolar da T.l. Maró em Rodrigues (2015). 
sofreu um duro golpe. Ele foi paralisado por expedição de sentença da Justiça federal brasileira que negava a existência destes indígenas e determinava o fracionamento do território em lotes destinando-os às "famílias tradicionais" que lá habitavam32. A alegação da sentença para a inexistência dos Borari e Arapium foi fundamentada em um suposto processo de miscigenação dos indígenas da região com migrantes nordestinos que teriam se instalado na região na época da borracha e subsumido por completo a identidade indígena. O prolator da sentença utiliza informações duvidosas retiradas da grande imprensa nacional supostamente publicadas como matérias pagas ${ }^{33}$ para justificar seus argumentos de miscigenação e apagamento da identidade étnica.

No entanto, a sentença foi emitida em um contexto em que empresas madeireiras foram pegas retirando madeiras do interior do território indígena. Os Borari-Arapium protestaram junto à FUNAI que acionou o Instituto Brasileiro do Meio Ambiente e dos Recursos Naturais (IBAMA), a Secretaria Estadual de Meio Ambiente e sustentabilidade (SEMAS) do Estado do Pará e representantes de empresas madeireiras que atuavam na região. O IBAMA, descobriu que a SEMAS havia autorizado planos de manejo florestal no interior do território embargando-os por se tratar de área indígena cuja jurisdição cabe à União, e não ao estado do Pará34.

Ato contínuo, os representantes dos empreendimentos empresariais interessados na incorporação dos recursos naturais do território ao comércio acionam a Justiça federal que, arbitrariamente, emite a referida sentença. Porém, em decisão de segundo grau a Justiça federal brasileira cancelou a

\footnotetext{
32 Confira a sentença em:

http://www.prpa.mpf.mp.br/news/2015/arquivos/Sentenca_TI_Maro.pdf.

${ }_{33}$ Confira o artigo 'A farra da antropologia oportunista', publicado na edição de 5 de maio de 2010 da Revista Veja.

34 Para maiores detalhes desse episódio conferir as páginas 189-199 do seguinte documento: http://repositorio.unicamp.br/bitstream/REPOSIP/305041/1/Rodrigues_GilbertoCesarLopes_D. pdf
} 
sentença do primeiro grau determinando a FUNAI a retomada do processo demarcatório 35 .

Contrariados com a sentença judicial que negava o pertencimento étnico indígena aos Borari e Arapium, a reação envolveu o fortalecimento das atividades escolares ligadas à reafirmação identitária indígena, e a determinação em movimentar a escola para incluir atividades de defesa e vigilância do território. Concretizou-se uma ideia que já vinha sendo esboçada com o descontentamento em mobilizar a escola nas comemorações tradicionais da Semana da Pátria, já entendidas como inadequadas ao propósito de afirmação identitária. Ocorreu uma espécie de síntese em torno da seguinte ideia: 'nós somos indígenas e essa sociedade nacional que nega isso não merece ter seus símbolos reverenciados nas atividades escolares. Vamos utilizar os períodos de comemorações dos símbolos nacionais para fortalecer a cultura indígena e defesa do território36". A "Semana da Pátria" foi o primeiro símbolo nacional de grande porte reelaborado por dentro das atividades escolares. Desde 2014 os professores indígenas vinham construindo a ideia de reelaborar a atividade escolar em torno do 7 de setembro e fazer dela instrumento de fortalecimento identitário e de manutenção do território. Com a síntese provocada pela sentença, colocaram em prática o Projeto de Vivência em Notório Saber e Língua Indígena.

Impulsionado pelos professores indígenas o "Projeto de Vivência em Notório Saber e Língua Nheengatu" foi posto em prática na semana da pátria de 2015 e envolveu uma série de atividades de ensino que extrapolaram os limites físicos da escola. Eles levaram alunos juntamente com caciques, pajé, caçadores, guerreiros e apoiadores para percorrerem o território e mostrar sua extensão aos alunos e desenvolver o sentimento de pertencimento a todo ele, tendo em vista a reclusão ao espaço no entorno da aldeia provocada pelas frequentes investidas dos agentes do capital e

35 Mais detalhes da anulação da sentença em: http://terradedireitos.org.br/wpcontent/uploads/2015/03/Decis\%C3\%A3o-Efeito-Suspensivo.pdf

36 Síntese das falas dos professorer de Notório Saber e Língua Indígena Nheengatu. 
do estado. Nessas aulas ensinaram sobre os locais sagrados, os encantados, as árvores medicinais, os igarapés, as caças e as estradas da mata expandindo nos alunos o conhecimento sobre o território. Para marcar a reelaboração teceram um cocar que foi içado no lugar da bandeira nacional no dia 7 de setembro daquele ano. Essa atividade vem se repetindo anualmente e desde então passou a integrar o calendário oficial da escola ${ }^{37}$.

As atividades são centralizadas em um local chamado por eles de Centro de Apoio da T.I. Maró. Esse centro resulta da retomada de uma casa de madeira de dois pavimentos construídas por posseiros madeireiros em área do interior da T.l. que foi recuperada pelos indígenas em outubro de 2014, no contexto de embargo dos planos de manejo florestal descritos acima e que antecedeu e impulsionou a sentença mencionada que declarou a inexistência dos Borari e Arapium do Maró. Para dar força ao processo de retomada territorial a casa foi transformada em um espaço de apoio para caça, atividades de preservação territorial e formação teórica e alimentou a esperança de reconquistar outras construções ilegais no interior da T.I.

Nesse sentido, levar as atividades escolares em torno do 7 de setembro para o Centro de Apoio representa um grande valor simbólico de resistência, autonomia e defesa territorial ao envolve-la na preservação dos espaços retomados. No caso tratar-se de um espaço (casa) recuperado de posseiros e distante $12 \mathrm{~km}$ da aldeia mais próxima envolto pelos últimos redutos de floresta primária da região.

Portanto, o ano de 2015 marca uma virada nas atividades escolares da T.I. Maró configurando-se de um lado como importante caminho na direção da consolidação de Notório Saber e Lingua Indígena Nheengatu enquanto disciplinas importantes para a educação diferenciada. Por outro lado, insere a escola firmemente no processo de territorialização conforme possibilita as diretrizes nacionais para a educação indígena.

37 Maiores detalhes em Rodrigues (2016) e Dias e Rodrigues (2017). 


\section{CONSIDERAÇÕES FINAIS}

O propósito desse trabalho foi analisar articulações entre educação escolar indígena e territorialização. Explicitamos as possiblidades normativas e práticas dessa articulação através do exame da legislação e de um caso concreto. Recorremos a Pachaco de Oliveira (1998) e Little (2002) para compreensão do conceito de território e seus correlatos territórilidade, territorialização e espaços territoriais e a aplicamos no entendimento desses termos na legislação brasileira sobre educação indígena.

Do ponto de vista teórico, concluímos que o uso do conceito de território e seus correlatos na legislação se identifica com o entendimento dos autores utilizados no sentido de significar o lugar geográfico que garante a sobrevivência física e identitária. Abrange o que Litte (2002) chamou de 'espaço biofísico' necessário a reprodução material e cultural, ou a 'base territorial fixa' de Pacheco de Oliveira (2002).

Do ponto de vista prático, as atividades que descrevemos tem se mostrado importante no processo de construção da escola diferenciada indígena. A novidade foi enfrentar o desafio de mobilizar a escola nos processos de territorialização.

O que pudemos presenciar, além de envolver um conjunto de práticas relativamente interdisciplinares amalgamadas sobre o nome Notório Saber e Língua Indígena Nheengatu, envolveu o espalhamento das atividades para além das fronteiras físicas da escola. Suas atividades foram levadas para o interior da floresta e para espaços reconquistados incorporando a ela, além da inclusão dos ensinamentos já conquistados de conteúdos próprios dos Borari e Arapium, atividades de preservação, vigilância e posse territorial.

Ademais, é preciso considerar que após séculos de pressão para o desaparecimento das sociedades indígenas e o consequente processo de invisibilização posto em prática como estratégia de sobrevivência (IORIS, 2009), não é possível, como defende Sampaio (2009), projetar sobre eles um tipo de educação diferenciada que preexiste. As sociedades indígenas são diferentes da sociedade nacional e entre si. Por isso cada sociedade dessa natureza deve ter autonomia para construir sua escola diferenciada e 
escolher os conteúdos que as distinguem e dão sentido a seu modo de viver e mobilizar os mecanismos necessários para utilização da escola como elemento de defesa do território, além da preservação identitária. Por isso, talvez, devamos pensar em 'escolas diferenciadas indígenas' ampliando o singular 'educação escolar indígena'

O projeto que acompanhamos e aqui relatamos configurou-se como um importante caminho em direção a construção da escola diferenciada indígena dos Borari e Arapium do Maró. O mais paradoxal sobre esse uso da escola é que "é processada dentro de um quadro político preciso, cujos parâmetros estão dados pelo Estado-nação" (WILLIAMS 1989, apud PACHECO DE OLIVIERA 1998, p. 58).

Neste sentido, e considerando que a pressão pela exploração dos recursos naturais ${ }^{38}$ presentes no interior da T.I. Maró levou o Estado, através da Justiça federal do Primeiro Grau do Pará, a defender que os moradores da T.I. Maró seriam falsos índios (SENTENÇA, 2014) determinando à FUNAI a paralisação do processo de demarcação desta T.I., somada as constantes veiculações na mídia local da falsidade dos indígenas do baixo Tapajós, o papel da escola diferenciada enquanto resgate identitário e defesa territorial ganha dimensões importantes e transforma a escola em uma flecha que devidamente utilizada contribui para a defesa do território.

No entanto, o desafio que se põe é a continuidade desse tipo de atividade diferenciada que anualmente mobiliza a escola na vigilância e manutenção territorial em um contexto de pouco (ou quase nenhum) apoio das estruturas estatais. Todos os anos que acompanhamos essas atividades elas contaram com apoio de parceiros sensíveis a causa e com uma imensa determinação dos professores, direção e lideranças. Dificuldade que conduz ao problema de realizar 'apenas' uma atividade desse tipo por ano. Ou seja, vigiar o território por meio das atividades escolares apenas uma vez ao ano pode não condizer com a resistência que o contexto de intensa exploração 38 Recentemente circulou a informação que mapas da Alcoa, atráves da Mineradora Rio do
Norte (MRN) confirmavam a existência de bauxita no interior da T.l. Maró.

Revista Exitus, Santarém/PA, Vol. 8, №3, p. 396 - 422, SET/DEZ 2018. 
madeireira, imobiliária e mineral requer. Mas, no campo educacional, é a flexa que se dispõe no momento e a ela devemos recorrer.

\section{REFERÊNCIAS}

ALMEIDA, A. W.; et al (Org.). Capitalismo Globalizado e Recursos Territoriais: Fonteiras da acumulação no Brasil Contemporâneo. Rio de janeiro: Lamparina, 2010.

BARTOLOMĖ, M. A. As etnogêneses: velhos atores e novos papéis no cenário cultural e político. Revista Maná. Rio de Janeiro: 2006, p. 39-68. Disponível em: http://www.scielo.br/scielo.php?.pid=\$0104132006000100002\&script=sci_arttex t. Acesso em: 20 de março de 2014.

BRASIL, Constituição da República Federativa do Brasil. Brasília: Congresso Nacional, 1988.

BRASIL. Diretrizes Nacionais para o Funcionamento das Escolas Indígenas. Brasília: MEC/CNE/CEB, 1999. Disponível em: http://portal.mec.gov.br/cne/arquivos/pdf/rceb03_99.pdf. Acessado em 20 de abril de 2014.

BRASIL. Diretrizes Curriculares Nacionais para a Educação Escolar Indígena no Ensino Básico. Brasília: MEC/CNE/CEB, 2003. Disponível em: http://portal.mec.gov.br/secretaria-de-regulacao-e-supervisao-daeducacao-superior-seres/323-secretarias- 112877938 /orgaos-vinculados82187207/17417-ceb-2012. Acessado em 20 de maio de 2018.

BRASIL. Diretrizes Curriculares Nacionais para a Educação Básica: diversidade e inclusão. Brasília: Conselho Nacional de Educação/Ministério da Educação/Secretaria de Educação Continuada, Alfabetização, Diversidade e Inclusão, 2013.

BRASIL. Plano Nacional de Educação (2014-2024). Brasília: Câmara dos Deputados, 2014. Disponível em:

http://www.observatoriodopne.org.br/uploads/reference/file/439/document o-referencia.pdf. Acesso em: 12 jun. 2018

BRASIL. Lei de Diretrizes e Bases da Educação Nacional. Brasília: Senado Federal, 2017. Disponível em:

http://www2.senado.leg.br/bdsf/bitstream/handle/id/529732/lei_de_diretrizes _e_bases_led.pdf. Acesso em: 24 jun. 2018.

DIAS, B.; RODRIGUES, G.C.L. Tudo Sai da Floresta. In: Conselho Indigenista Missionário - CIMI, 2017. Disponível em: 
https://www.cimi.org.br/2017/09/40958/. Acessado em 20 de novembro de 2017.

FUNAI. Fundação Nacional do Índio. Processo 08620.000294/2010. Brasília: DOU/FUNAl, 2010.

IORIS, E. Identidades negadas, identidades construídas: processos identitários e conflitos territoriais na Amazônia. ILHA - Revista de Antropologia.

Florianópolis: UFSC, 2009. v.11, n.2, p.220-264. Disponível em https://periodicos.ufsc.br/index.php/ilha/article/view/2175-8034.2009v1 ln 12p219. Acesso em: 05 maio 2014.

JUSTIÇA FEDERAL DE PRIMEIRO GRAU NO PARÁ. Sentença ao processo 2010.39.02.000249-0 e 2091-80.2010.4.01.3902. Santarém: Justiça Federal de Primeiro Grau no Pará, 2014. Disponível em: http://www.prpa.mpf.mp.br/news/2015/arquivos/Sentenca_TI_Maro.pdf. Acesso em: 03 de março de 2016.

LITTLE, P. Territórios Sociais e Povos Tradicionais no Brasil: Por uma antropologia da territorialidade. (Série Antropologia, n 322). Brasília: Unb, 2002. Disponível em:

http://www.direito.mppr.mp.br/arquivos/File/PaulLittle.pdf Acesso em: 05 de março de 2018.

PACHECO DE OLIVEIRA, J. Uma Ełnologia dos "Índios Misturados"?: situação colonial, territorialização e fluxos culturais. Rio de Janeiro: Revista Mana, 4.1, p.47-77, 1998. Disponível em: http://www.scielo.br/pdf/mana/v4n1/2426.pdf. Acesso em: 03 de março de 2018.

RODRIGUES, G. C. L. R. A Educação Escolar na Terra Indígena Maró: aproximações. In: Revista Eletrônica Ñanduły. Dourados, MS: Programa de Pós Graduação em Antropologia/Universidade Federal da Grande Dourados, 2015, v.3, n.3. p.84-93. Disponível em: http://www.periodicos.ufgd.edu.br/index.php/nanduty/article/viewArticle/37 16. Acessado em 14 de junho de 2015.

RODRIGUES, G. C. L. R. Surara Borari, Surara Arapium. A Educação Escolar no Processo de reafirmação étnica dos Borari e Arapium da Terra Indígena Maró. (Tese de Doutorado). Campinas: Unicamp, 2016. Disponível em: http://repositorio.unicamp.br/bitstream/REPOSIP/305041/1/Rodrigues_Gilberto CesarLopes_D.pdf. Acessado em 14 de junho de 2017.

SAMPAIO, J. A. L. O "Resgate Cultural" como valor: reflexões sobre experiências de um antropólogo militante em programas de formação de professores indígenas no Nordeste e em Minas Gerais. In: PIORSKYAIRES (Org.). As Escolas Indígenas e Políticas Interculturais no Nordeste Brasileiro. Fortaleza: EDUECE, 2009. 
SANTOS, S. C. Educação e Sociedades Tribais. Porto Alegre: Editora Movimento, 1975.

SAUER, S. PEREIRA, J. M. M. Capturando a Terra: Bando Mundial, políticas fundiárias neoliberais e reforma agrária de mercado. São Paulo: Expressão Popular, 2006.

SILVA, G. da. Relatório Circunstanciado de Identificação e Delimitação dos Limites da Terra Indígena Maró, Elaborado Conforme Portaria No 14/MJ/1996. In: Processo FUNAI 08620.000294/2010. Brasília: FUNAI/MJ, 2011.

SOUZA FILHO, C. F. M. de. O renascer dos povos indígenas para o Direito. Curitiba: Juruá Editora, 1999.

Recebido em: Janeiro de 2018 Aprovado em: Junho de 2018 